\title{
Effects of centrally acting antihypertensive drugs on the microcirculation of spontaneously hypertensive rats
}

\section{Estato ${ }^{1}$, \\ C.V. Araújo ${ }^{1}$, \\ P. Bousquet ${ }^{2}$ and \\ E. Tibiriçá ${ }^{1}$}

\author{
1'Departamento de Fisiologia e Farmacodinâmica, Instituto Oswaldo Cruz, \\ FIOCRUZ, Rio de Janeiro, RJ, Brasil \\ ${ }^{2}$ Laboratoire de Neurobiologie et Pharmacologie Cardiovasculaire, \\ Faculté de Médecine, Université Louis Pasteur, Strasbourg, France
}

\author{
Correspondence \\ E. Tibiriçá \\ Departamento de Fisiologia e \\ Farmacodinâmica \\ Instituto Oswaldo Cruz, FIOCRUZ \\ Av. Brasil, 4365 \\ 21045-900 Rio de Janeiro, RJ \\ Brasil \\ Fax: +55-21-2598-4451 \\ E-mail: etibi@ioc.fiocruz.br \\ Research supported by CNPq and \\ FAPERJ, as well as FIOCRUZ \\ (Fundação Oswaldo Cruz). \\ $\ldots \ldots \ldots \ldots \ldots \ldots \ldots$
}

Received January 21, 2004 Accepted June 24, 2004

\begin{abstract}
We investigated the acute effects of centrally acting antihypertensive drugs on the microcirculation of pentobarbital-anesthetized spontaneously hypertensive rats (SHR). The effects of the sympatho-inhibitory agents clonidine and rilmenidine, known to activate both $\alpha_{2}$-adrenoceptors and nonadrenergic $\mathrm{I}_{1}$-imidazoline binding sites $\left(\mathrm{I}_{1} \mathrm{BS}\right)$ in the central nervous system, were compared to those of dicyclopropylmethyl-(4,5-dimethyl-4,5-dihydro-3 $H$-pyrrol-2-yl)-amine hydrochloride (LNP 509), which selectively binds to the $\mathrm{I}_{1} \mathrm{BS}$. Terminal mesenteric arterioles were observed by intravital microscopy. Activation of the central sympathetic system with L-glutamate $(125 \mu \mathrm{g}, i c)$ induced marked vasoconstriction of the mesenteric microcirculation $(27 \pm 3 \%$; $\mathrm{N}=6, \mathrm{P}<0.05$ ). In contrast, the marked hypotensive and bradycardic effects elicited by intracisternal injection of clonidine $(1 \mu \mathrm{g})$, rilmenidine $(7 \mu \mathrm{g})$ and LNP $509(60 \mu \mathrm{g})$ were accompanied by significant increases in arteriolar diameter $(12 \pm 1,25 \pm 10$ and $21 \pm 4 \%$, respectively; $\mathrm{N}=6, \mathrm{P}<0.05)$. The vasodilating effects of rilmenidine and LNP 509 were two-fold higher than those of clonidine, although they induced an identical hypotensive effect. Central sympathetic inhibition elicited by baclofen $(1 \mu \mathrm{g}, i c)$, a GABA $A_{\mathrm{B}}$ receptor agonist, also resulted in vasodilation of the SHR microvessels. The acute administration of clonidine, rilmenidine and LNP 509 also induced a significant decrease of cardiac output, whereas a decrease in systemic vascular resistance was observed only after rilmenidine and LNP 509. We conclude that the normalization of blood pressure in SHR induced by centrally acting antihypertensive agents is paralleled by important vasodilation of the mesenteric microcirculation. This effect is more pronounced with substances acting preferentially (rilmenidine) or exclusively (LNP 509) upon $\mathrm{I}_{1} \mathrm{BS}$ than with those presenting important $\alpha_{2}$-adrenergic activity (clonidine).
\end{abstract}

Key words

- Mesenteric microcirculation

- Arterial hypertension

- Clonidine

- Rilmenidine

- Baclofen

- LNP 509

.......................... 


\section{Introduction}

Chronic elevation of peripheral vascular resistance is considered to be the major hemodynamic alteration in the established phase of human essential hypertension (1). It is also well known that most of this increased vascular resistance is determined at the microvascular level, resulting mainly from functional (changes in vascular reactivity) and/or structural (increased arteriolar wall-to-lumen ratio) abnormalities (2,3). Moreover, several lines of evidence suggest that a reduction in the density per volume of tissue (rarefaction) of small arterioles and capillaries contributes significantly to the elevation of resistance and consequently of blood pressure in essential hypertension $(4,5)$.

Although the microcirculation plays a causative role in certain forms of hypertension, it may also represent a preferential target of this disease (6). Thus, in addition to the apparent blood pressure lowering effects, which are similar between the different classes of drugs used in the treatment of high blood pressure, antihypertensive therapy should also be able to prevent and/or reverse functional and structural changes of the microcirculation $(7,8)$.

The central sympathetic nervous system plays a major role in the control of vascular resistance (9). Moreover, several experimental and clinical evidence support the hypothesis that an elevated sympathetic control of vascular tone is one of the major causal factors in the development of hypertension, as well as in the induction of trophic effects such as cardiac and vascular hypertrophy/remodeling (for a review, see Ref. 10). Sympathetic hyperactivity can be effectively modulated by drugs acting directly on its site of origin, i.e., the central nervous system (CNS). In this context, first generation centrally acting antihypertensive drugs such as clonidine have long been used in the treatment of essential arterial hypertension (11). Nevertheless, the antihypertensive effect of this class of drugs was fre- quently accompanied by important central side effects such as sedation and dry mouth resulting in a loss of interest in its clinical use (11).

Since then, the existence of specific binding sites for these drugs characterized by their lack of sensitivity to catecholamines has been demonstrated in the CNS, i.e., the nonadrenergic $\mathrm{I}_{1}$-imidazoline binding sites $\left(\mathrm{I}_{1} \mathrm{BS}\right)(12,13)$. The dissociation of the pharmacological mechanisms involved in the hypotensive effect of clonidine-like drugs (imidazoline binding sites in the ventrolateral medulla) (14-16) and the one responsible for their sedative action ( $\alpha_{2}$-adrenoceptors in the locus coeruleus) $(14,17)$ was also established. As a result, a second generation of centrally acting antihypertensive drugs has been developed. In fact, new drugs such as rilmenidine and moxonidine have proved to be effective in the treatment of mild to moderate arterial hypertension without significant sedative effects (18). In the present study we also used a new pharmacological tool, dicyclopropylmethyl-(4,5-dimethyl4,5-dihydro-3H-pyrrol-2-yl)-amine hydrochloride (LNP 509), which has been shown to bind selectively to the $\mathrm{I}_{1} \mathrm{BS}$, having no affinity for $\alpha_{2^{-}}$and $\alpha_{1}$-adrenoceptors or activity on $\alpha_{2}{ }^{-}$ adrenoceptors $(19,20)$.

The present study was designed to investigate the in vivo microcirculatory modifications induced by centrally acting antihypertensive agents in anesthetized spontaneously hypertensive rats (SHR). We hypothesized that the antihypertensive effects of these drugs could be associated to significant vasodilation of the SHR microvessels, resulting from the inhibition of sympatho-excitatory neurons in the brainstem. Intravital video microscopy was used to assess the microcirculatory parameters of the rat mesentery during central administration of drugs.

\section{Material and Methods}

\section{General procedures}

All procedures were approved by the 
Animal Welfare Committee of the Oswaldo Cruz Foundation and were consistent with the USA National Institutes of Health Guide for the Care and Use of Laboratory Animals (NIH Publication No. 85-23, revised 1996). Twelve- to 16-week-old male SHR derived from the Okamoto-Aoki strain (UNIFESP, São Paulo, SP, Brazil) were housed 4 per cage with a 12-h light/dark cycle and had free access to tap water and standard pellet food. Before the experiment, animals were fasted overnight but given water ad libitum in order to minimize peristaltic movements of the intestine. The animals were anesthetized with sodium pentobarbital $(50 \mathrm{mg} / \mathrm{kg}$, $i p$ ), tracheostomized, immobilized with pancuronium bromide ( $1 \mathrm{mg} / \mathrm{kg}, i v)$, and artificially ventilated with room air (tidal volume, $10 \mathrm{ml} / \mathrm{kg}$, stroke rate $45 / \mathrm{min}$ ); anesthesia was complemented hourly with ip injections of $5 \mathrm{mg} / \mathrm{kg}$ pentobarbital. The rats were then placed on a surgical table and a rectal thermometer was inserted. The thermometer was connected to a temperature monitor (Effenberger, Kirchheim, Germany), which maintained temperature constant at $37^{\circ} \mathrm{C}$ with a thermal pad during all procedures. The right femoral vein was catheterized to permit ip injections. Arterial pressure was continuously monitored with a catheter placed in the right carotid artery connected to a Hewlett Packard (Palo Alto, CA, USA) quartz transducer (1290 A), which in turn was connected to a pressure processor and recorder (Hewlett Packard 7754 system with 8805B amplifier). Systolic (SAP) and diastolic (DAP) arterial pressures were obtained directly from the recordings. The mean arterial pressure (MAP) was calculated as diastolic pressure plus one third of the differential pressure; heart rate (HR) was counted from the blood pressure waves by rapid running of the pressure recording. The abdomen was carefully opened by a small midline incision, the rat was then placed on its side on a plate support and the ileojejunal part of the mesentery was exteriorized carefully and arranged in such a way that the mesentery came to lie over a transparent plate set, exactly above the window light source of the microscope. To prevent drying of the exposed mesentery, we used a plate support containing a continuous water circulating system inside at $37^{\circ} \mathrm{C}$ and covered it with plastic film.

\section{Cardiac output measurements}

In separate groups of animals a thoracotomy was performed via a left intercostal incision between the second and third ribs. The heart was exposed by incising the pericardium and the aorta was isolated from contiguous structures and freed from adventitia and adipose tissue at the site of the flow measurements. An electromagnetic flow probe was then placed around the ascending aorta and connected to a blood flowmeter (Skalar model MDL 1401, Litchfield, Canada) and cardiac output ( $\mathrm{CO}, \mathrm{ml} / \mathrm{min}$ ) was recorded continuously with the above-mentioned recorder. Systemic vascular resistance (SVR) was calculated as the quotient of the MAP and the CO multiplied by a conversion factor (80) and reported as dyn s-1 $\left(\mathrm{cm}^{5}\right)^{-1}$.

\section{Intravital microscopy}

After surgery, the animal was transferred to a fixed-stage upright intravital videomicroscopy (Olympus BX5-1WL, Melville, NY, USA) coupled to a CCD video camera (Samsung BW 273A, Seoul, Korea). Observations were made using conventional transillumination with a $10 \mathrm{X}$ eyepiece and $10 \mathrm{X}$ objectives (Olympus) with final magnification of 100X. Video images were displayed on a video monitor (National, Tokyo, Japan) coupled to a time-date generator and stored in a videocassette recorder (VHS VC 1694B; Sharp, Manaus, AM, Brazil) for off-line analyses. The selected pictures (six images for each time point) were captured and processed for static display with a specialized software (Ecoview ImagePro, Media Cyber- 
netics Inc., Silver Springs, MD, USA), and suitable unbranched arterioles with diameters between 15 and $30 \mu \mathrm{m}$ were selected. Arteriolar diameters were measured as the distance between the two clearly defined muscular walls and expressed in $\mu \mathrm{m}$. The data were automatically transferred to the Microsoft ${ }^{\circledR}$ Excel for calculations.

\section{Intracisternal injections}

The head of the animal was fixed in a stereotaxic apparatus (Stoelting, Wood Dale, IL, USA). A craniotomy was performed, the cisterna magna was localized with stereotaxic coordinates and the needle was fixed on the skull with dental cement for drug administration $(10 \mu \mathrm{l})$. At the end of the experiment, the same volume of Evans blue dye was injected under the same conditions. The brain was removed post mortem and dissected to determine if the drugs had diffused properly and which structures were reached.

\section{Experimental protocol}

After completion of the surgical procedures, the animals were allowed to equilibrate for 30 min or until a stable tracing had been obtained (control period). Before drug injection, the means of three arterial pressure measurements (SAP, DAP and MAP), $\mathrm{HR}$ and $\mathrm{CO}$, recorded at 5-min intervals, were calculated and considered as the basal hemodynamic values. The microvascular parameters of the arterioles and venules were recorded for $2 \mathrm{~min}$ at 10-min intervals throughout the experimental period $(\approx 120$ min).

\section{Drugs}

The following drugs were used: sodium pentobarbital, pancuronium bromide, L-glutamate, baclofen, and clonidine hydrochloride, purchased from Sigma (St. Louis, MO,
USA). Rilmenidine (2-[N-(dicyclopropylmethyl)amino]oxazoline) was kindly provided by Institut de Recherches Internationales Servier (Courbevoie, France). LNP 509 (dicyclopropylmethyl-(4,5-dimethyl-4,5-dihydro$3 H$-pyrrol-2-yl)-amine hydrochloride was from the Laboratoire de Neurobiologie et Pharmacologie Cardiovasculaire (LNPCV), Université Louis Pasteur (Strasbourg, France). Drugs were dissolved in saline ( $0.9 \%$ $(\mathrm{w} / \mathrm{v}) \mathrm{NaCl})$.

\section{Statistical analysis}

All data are reported as mean \pm SEM for each group of 6 rats. Comparisons between the groups were made with one-way ANOVA and within-group variations with time were analyzed by repeated measures ANOVA. When an overall difference was detected by ANOVA, the Student-Newman-Keuls test was used to localize the statistically significant differences. $\mathrm{P}$ values of less than 0.05 were considered to be significant. All calculations were made by computer-assisted analyses using a commercially available statistical package (Graphpad Instat, Graphpad Software, University of London, UK).

\section{Results}

\section{Central cardiovascular effects of clonidine, rilmenidine and LNP 509}

There were no significant differences in baseline blood pressure, HR or CO between experimental groups, as shown by ANOVA $(\mathrm{P}>0.05)$. The intracisternal (ic) injection of $1 \mu \mathrm{g}$ clonidine and $7 \mu \mathrm{g}$ rilmenidine elicited marked and long-lasting antihypertensive effects characterized by a maximum decrease on MAP of $53 \pm 3$ and $50 \pm 8 \%$, respectively $(\mathrm{N}=6, \mathrm{P}<0.05$; Figure 1 and Table 1$) . \mathrm{HR}$ was significantly reduced by both drugs, reaching a maximum of $30 \pm 2$ and $19 \pm 5 \%$, respectively $(\mathrm{N}=6, \mathrm{P}<0.05)$. The central administration of clonidine and rilmenidine 
also induced a significant decrease of $\mathrm{CO}$ $(50 \pm 10$ and $39 \pm 2 \%$, respectively; $N=6, P$ $<0.05)$ whereas there was a significant decrease in SVR of $24 \pm 7 \%(\mathrm{~N}=6, \mathrm{P}<0.05)$ only after rilmenidine (Figure 1 and Table 1). The central administration of $60 \mu \mathrm{g}$ LNP 509 evoked effects similar to those of clonidine and rilmenidine on MAP, the maximum reduction being of $56 \pm 4 \%(\mathrm{~N}=6, \mathrm{P}<0.05)$. The effects of LNP 509 on CO $(-22 \pm 3 \%, \mathrm{~N}$ $=6, \mathrm{P}<0.05)$ and on SVR $(-28 \pm 6 \% ; \mathrm{N}=6$, $\mathrm{P}<0.05)$ were significantly different from those observed after clonidine treatment (Figure 1 and Table 1). On the other hand, $60 \mu \mathrm{g}$ ic LNP 509 had no significant effect on HR (Figure 1 and Table 1).
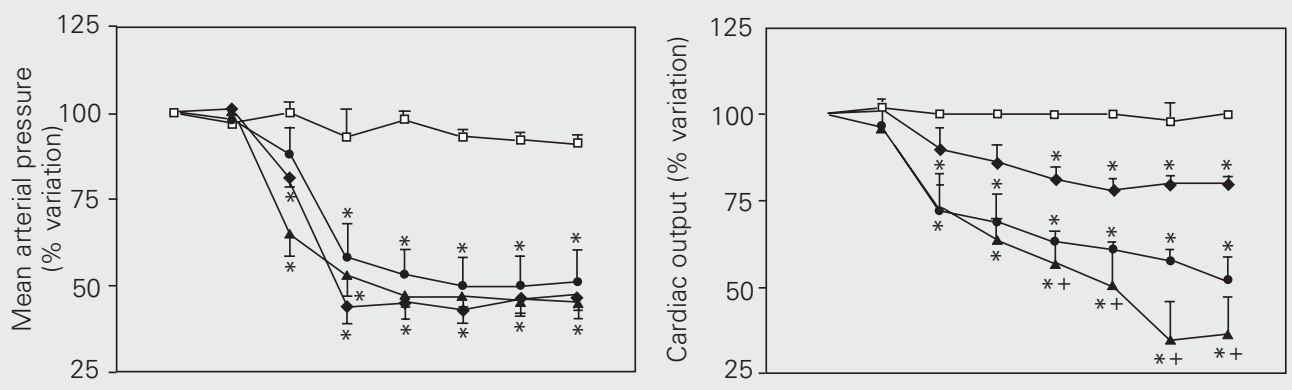

Figure 1. Time course of the hemodynamic changes in response to intracisternal injection of saline (SAL, control group), clonidine (CLO, $1 \mu \mathrm{g}$ ), rilmenidine (RIL, $7 \mu \mathrm{g})$, or LNP 509 (LNP, $60 \mu \mathrm{g})$ in anesthetized spontaneously hypertensive rats. Each set of points represents the mean \pm SEM for 6 experiments. ${ }^{*} P<0.05$ compared to the control group. ${ }^{+} \mathrm{P}<0.05$ compared to the clonidinetreated group (ANOVA).
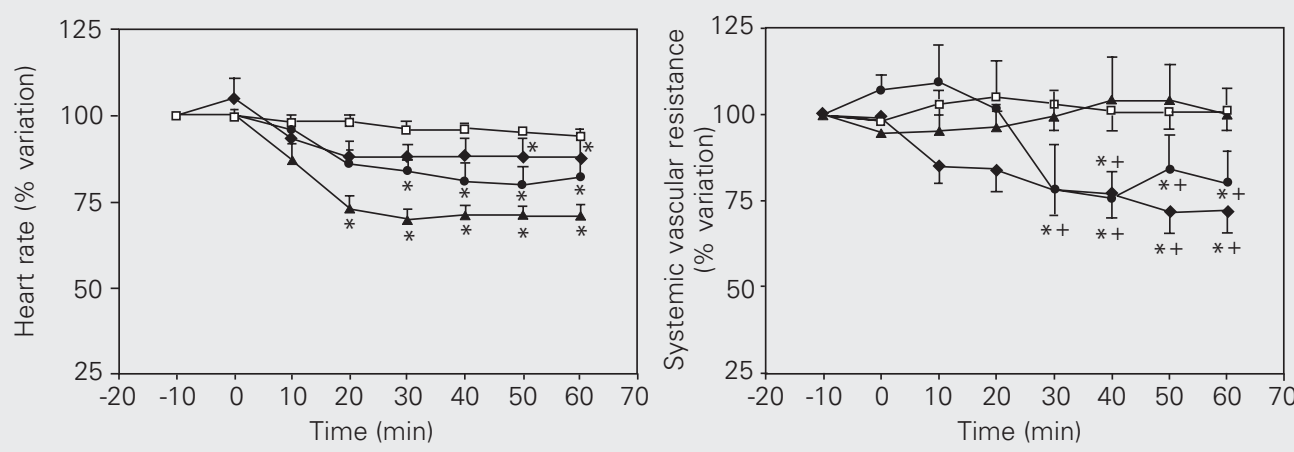

$\square S A L$

$\Delta \mathrm{CLO}$

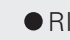

RIL

LNP

Table 1. Maximum effects of the intracisternal injection of clonidine $(1 \mu \mathrm{g})$, or LNP $509(60 \mu \mathrm{g})$ on the macrohemodynamic parameters of pentobarbital-anesthetized spontaneously hypertensive rats.

\begin{tabular}{|c|c|c|c|c|c|c|c|c|}
\hline & \multicolumn{2}{|c|}{ Saline } & \multicolumn{2}{|c|}{ Clonidine } & \multicolumn{2}{|c|}{ Rilmenidine } & \multicolumn{2}{|c|}{ LNP 509} \\
\hline & Before & After & Before & After & Before & After & Before & After \\
\hline MAP $(\mathrm{mmHg})$ & $150 \pm 6$ & $147 \pm 7$ & $157 \pm 10$ & $74 \pm 7^{*}$ & $146 \pm 7$ & $74 \pm 16^{*}$ & $153 \pm 8$ & $68 \pm 8^{*}$ \\
\hline HR (bpm) & $424 \pm 11$ & $405 \pm 9$ & $405 \pm 9$ & $281 \pm 7^{*}$ & $451 \pm 19$ & $365 \pm 15^{*}$ & $417 \pm 33$ & $380 \pm 29 *$ \\
\hline $\mathrm{CO}(\mathrm{ml} / \mathrm{min})$ & $191 \pm 20$ & $191 \pm 19$ & $229 \pm 11$ & $129 \pm 11^{*}$ & $222 \pm 30$ & $137 \pm 16^{*}$ & $156 \pm 22$ & $122 \pm 16^{*}$ \\
\hline SVR $\left(\right.$ dyn s $\mathrm{s}^{-1}\left(\mathrm{~cm}^{5}\right)^{-1}$ & $52 \pm 2$ & $55 \pm 4$ & $46 \pm 3$ & $45 \pm 2$ & $52 \pm 7$ & $40 \pm 6^{*}$ & $69 \pm 6$ & $49 \pm 4^{*}$ \\
\hline
\end{tabular}

$\mathrm{CO}=$ cardiac output; $\mathrm{HR}=$ heart rate; $\mathrm{MAP}=$ mean arterial pressure; $\mathrm{SVR}=$ systemic vascular resistance. Each value represents the mean \pm SEM for 6 experiments.

${ }^{*} \mathrm{P}<0.05$ compared to basal values (ANOVA). 
Microcirculatory effects induced by ic injection of clonidine, rilmenidine and LNP 509

The hypotensive effect induced by ic injection of $1 \mu \mathrm{g}$ clonidine, $7 \mu \mathrm{g}$ rilmenidine and $60 \mu \mathrm{g}$ LNP 509 was accompanied by mesenteric arteriolar vasodilation, characterized by a maximum increase in arteriolar diameter of $12 \pm 1 \%(\mathrm{~N}=6, \mathrm{P}<0.05), 25 \pm$ $10 \%(\mathrm{~N}=6, \mathrm{P}<0.05)$ and $21 \pm 4 \%(\mathrm{~N}=6, \mathrm{P}$ $<0.05$; Figure 2 ) from the basal values of 19 $\pm 1.9,18.8 \pm 1.8$ and $22 \pm 1 \mu \mathrm{m}$, respectively.

\section{Cardiovascular and microcirculatory effects of ic injection of baclofen and L-glutamate}

The central ic injection of $1 \mu \mathrm{g}$ baclofen elicited marked and long-lasting decreases in MAP, with a maximum of $63 \pm 8 \%$ (from $155 \pm 7$ to $62 \pm 8 \mathrm{mmHg} ; \mathrm{N}=6, \mathrm{P}<0.05$; data not shown). HR decreased by $18 \pm 5 \%$ (from $390 \pm 11$ to $316 \pm 27 \mathrm{bpm} ; \mathrm{N}=6, \mathrm{P}>0.05$; data not shown). The hypotensive effect of baclofen was accompanied by significant vasodilation of the mesenteric microcirculation (Figure 2). The maximum increase of arteriolar diameter after baclofen was $11 \pm$ $4 \%$ (from $30 \pm 5$ to $33.5 \pm 5 \mu \mathrm{m} ; \mathrm{N}=6, \mathrm{P}>$ $0.05)$. On the other hand, the central ic administration of $125 \mu \mathrm{g}$ L-glutamate evoked a marked but short-lasting increase in MAP, reaching a maximum of $24 \pm 5 \%$ (from $161 \pm$ 9 to $198 \pm 9 \mathrm{mmHg} ; \mathrm{N}=6, \mathrm{P}<0.05$; data not

Figure 2. Maximum changes (percent of baseline) of mesenteric arteriolar diameter. Variations observed after intracisternal injection of saline (SAL, control group), clonidine (CLO, $1 \mu \mathrm{g}$ ), rilmenidine (RIL, $7 \mu \mathrm{g}$ ), LNP 509 (LNP, $60 \mu \mathrm{g}$ ), baclofen (BAC, 1 $\mu \mathrm{g}$ ), or L-glutamate (GLU, 125 $\mu g$ ) in anesthetized spontaneously hypertensive rats. Each set of points represents the mean \pm SEM for 6 experiments. ${ }^{*} P<0.05$ compared to the control group. ${ }^{+} P<0.05$ compared to the clonidine-treated group (ANOVA). shown). HR increased only by $6 \pm 2 \%$ (from $432 \pm 9$ to $458 \pm 5 \mathrm{bpm} ; \mathrm{N}=6, \mathrm{P}>0.05$; data not shown). The hypertensive effect of 125

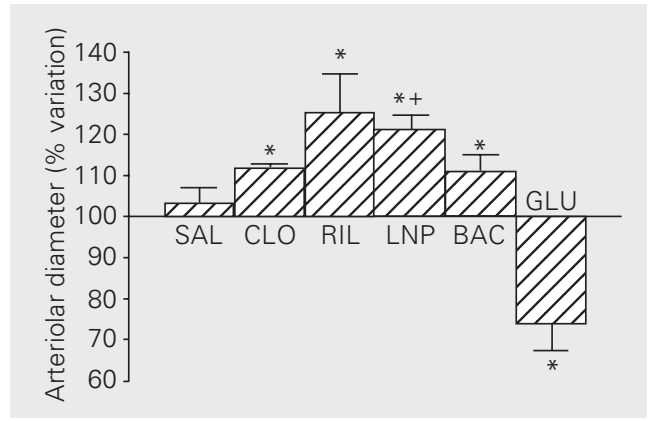

$\mu \mathrm{g} \mathrm{L}$-glutamate was accompanied by mesenteric arteriolar vasoconstriction, reaching the maximum of $27 \pm 3 \%(\mathrm{~N}=6, \mathrm{P}<0.05)$ from the basal value of $19.6 \pm 1.4 \mu \mathrm{m}$ (Figure 2 ).

\section{Discussion}

The present study is the first to demonstrate that acute administration of centrally acting antihypertensive drugs such as clonidine and rilmenidine significantly dilates the microcirculation of SHR. It is noteworthy that both drugs were injected directly into the CNS (intracisternally) in doses that do not present significant cardiovascular effects when administered systemically $(21,22)$. Thus, although the activation of peripheral $\alpha_{2}$-adrenoceptors in SHR also induces dilation of terminal arterioles (23), the arteriolar vasodilation observed in the present study cannot be due to the peripheral effects of clonidine.

The small arteries and arterioles of the microcirculation are well known to be the most important site of the increased vascular resistance in hypertensive patients (7). In SHR, the progressive development of hypertension is associated with an increase in arteriolar tone in different vascular beds (24) that reaches even the terminal arterioles (lumen diameter of about $20 \mu \mathrm{m})(25,26)$. Moreover, compared to normotensive control rats (Wistar-Kyoto), the vascular tone of SHR is set at a higher steady-state level (27). In this context, it has already been shown that a decrease of only $13 \%$ in arteriolar diameter is sufficient to produce an increase in systemic blood pressure of about $50 \mathrm{mmHg}$ (26). Moreover, since sympathetic hyperactivity is implicated in the development of arterial hypertension (28), modulation of the central sympathetic activity with centrally acting antihypertensive agents turns out to be a reasonable therapeutic target in the treatment of this disease.

We evaluated the microcirculatory behavior of SHR using the microcirculation of 
the mesentery, which is known to respond to peripheral or central sympathetic stimulation $(29,30)$. In fact, the mesenteric microvascular network appears to have a dense sympathetic innervation (31), which is increased in arterioles of SHR (32). Functional studies in the rat demonstrated that the electrical stimulation of the posterior hypothalamus induces an increase in MAP accompanied by a significant vasoconstrictor response of mesenteric arterioles (31), thus demonstrating that this particular vascular bed is under sympathetic control. Moreover, Le Noble et al. (33) showed that pentobarbital is the anesthetic of choice to be used in experimental studies assessing the mesenteric microcirculation of the rat, since it does not interfere with microvascular reactivity to adrenergic stimulation. Our results are consistent with these observations, since the pharmacological activation of the central sympathetic nervous system with intracisternal glutamate, the main excitatory neurotransmitter in the mammalian CNS, elicited marked arteriolar constriction in the mesentery.

Our results also demonstrate that the classical acute hemodynamic effects of centrally acting antihypertensive drugs (i.e., hypotension and bradycardia) are accompanied by significant dilatation of terminal arterioles in SHR. It is noteworthy that the vasodilating effects of rilmenidine and LNP 509 were much more pronounced than that of clonidine, thus supporting the view that different mechanisms might be involved in the antihypertensive effects of first- and second-generation drugs (11). Nevertheless, we did not investigate the pharmacological mechanisms involved in the microcirculatory effects of these drugs, which could be clarified by the use of selective antagonists. In fact, the present study was designed to test our hypothesis that the inhibition of the central sympathetic system could be accompanied by a significant dilation of the microcirculation in hypertensive animals.
The central acute administration of antihypertensive drugs also induced significant decreases in $\mathrm{CO}$, which were of greater magnitude in response to clonidine than rilmenidine or LNP 509. As a result, only rilmenidine and LNP 509 produced a significant fall in systemic vascular resistance. These results are consistent with those reported by Azevedo et al. (34), who showed that acute intravenous administration of clonidine elicits negative inotropic effects associated with the inhibition of cardiac-specific sympathetic outflow, evaluated by cardiac norepinephrine spillover in patients with congestive heart failure. The acute hypotensive effect of clonidine in anesthetized rats had been attributed mainly to a reduction in $\mathrm{CO}$ rather than in total peripheral resistance (35). On the other hand, in conscious and freely moving SHR, clonidine-induced hypotension seems to depend mainly on reduction of vascular resistance (36). The greater selectivity of rilmenidine for the $\mathrm{I}_{1} \mathrm{BS}$, when compared to the $\alpha_{2}$-adrenergic receptors $(11,15)$, could explain this preferential action on vascular resistance since LNP 509, which is devoid of $\alpha_{2}$-adrenergic-mediated cardiovascular activity $(19,20)$, elicited a hemodynamic profile similar to that of rilmenidine after intracisternal administration.

Our results also showed that the central administration of baclofen, a $\mathrm{GABA}_{\mathrm{B}}$ receptor agonist which inhibits the neuronal release of excitatory neurotransmitters such as glutamate (37), also induced significant dilation of the SHR microvessels. Moreover, it has already been demonstrated that the central GABA-ergic system exerts a tonic inhibitory effect on the central sympathetic system, and consequently on cardiovascular function (38). These findings confirm the hypothesis that the inhibition of the central sympathetic drive results in vasodilation of the microcirculation of hypertensive animals.

Finally, previous studies using the mesenteric vascular bed have shown that hemorrhagic hypotension in rats induces signifi- 
cant vasoconstriction of the microcirculation $(39,40)$, thus suggesting that the arteriolar vasodilation in the mesentery observed in the present study did not result from the large drop in arterial pressure induced by the antihypertensive drugs.

\section{Perspectives}

The results of the present study show that the reduction of blood pressure in the genetic model of arterial hypertension induced by centrally acting antihypertensive agents is paralleled by important vasodilation of the mesenteric microcirculation. This effect is more pronounced with substances acting preferentially (rilmenidine) or exclusively (LNP 509) upon nonadrenergic imidazoline binding sites than with those presenting important $\alpha_{2}$-adrenergic selectivity (clonidine). Since important functional and structural alterations of the microcirculation are involved in the pathophysiology of primary arterial hypertension, new therapeutic approaches should be able to prevent or even reverse these major features of the disease.

\section{Acknowledgments}

The authors gratefully acknowledge Mr. R. Cavalheiro-Silva for skillful technical assistance.

\section{References}

1. Conway J (1984). Hemodynamic aspects of essential hypertension in humans. Physiological Reviews, 64: 617-660.

2. Cooper A \& Heagerty A (1994). Small arteries and hypertension. Journal of Hypertension, 12: S33-S35.

3. Vicaut E (1999). Microcirculation and arterial hypertension. Drugs, 58 (Special issue 1): 1-10

4. Struijker-Boudier HA, Le Noble JL, Messing MW, Huijberts MS, Le Noble FA \& van Essen H (1992). The microcirculation and hypertension. Journal of Hypertension, 10: S147-S156.

5. Antonios TF, Singer DR, Markandu ND, Mortimer PS \& MacGregor GA (1999). Structural skin capillary rarefaction in essential hypertension. Hypertension, 33: 998-1001.

6. Mulvany MJ (2002). Small artery remodeling and significance in the development of hypertension. News in Physiological Sciences, 17: 105-109.

7. Levy BI, Ambrosio G, Pries AR \& Struijker-Boudier HA (2001). Microcirculation in hypertension: a new target for treatment? Circulation, 104: 735-740.

8. Ruilope LM \& Schiffrin EL (2001). Blood pressure control and benefits of antihypertensive therapy: does it make a difference which agents we use? Hypertension, 38 (Part 2): 537-542.

9. Chalmers JP, Kapoor V, Liewellyn-Smith IJ, Minson JB \& Pilowsky PM (1992). Central control of blood pressure. European Heart Journal, 13: 2-9.

10. Esler M (2000). The sympathetic system and hypertension. American Journal of Hypertension, 13 (Part 2): 99S-105S.

11. Bousquet $P$ \& Feldman J (1999). Drugs acting on imidazoline receptors: a review of their pharmacology, their use in blood pressure control and their potential interest in cardioprotection. Drugs, 58: 799-812

12. Bousquet P, Feldman J \& Schwartz J (1984). Central cardiovascular effects of alpha-adrenergic drugs: difference between catecholamines and imidazolines. Journal of Pharmacology and Experimental Therapeutics, 230: 232-236.

13. Reis DJ, Regunathan S, Wang H, Feinstein DL \& Meeley MP (1992).
Imidazoline receptors in the nervous system. Fundamental and Clinical Pharmacology, 6: 23S-29S.

14. Tibiriçá E, Feldman J, Mermet C, Gonon F \& Bousquet P (1991). An imidazoline-specific mechanism for the hypotensive effect of clonidine: a study with yohimbine and idazoxan. Journal of Pharmacology and Experimental Therapeutics, 256: 606-613.

15. Tibiriçá E, Feldman J, Mermet C, Monassier L, Gonon F \& Bousquet $P$ (1991). Selectivity of rilmenidine for the nucleus reticularis lateralis, a ventrolateral medullary structure containing imidazoline-preferring receptors. European Journal of Pharmacology, 209: 213-221.

16. Chan CK, Sannajust F \& Head GA (1996). Role of imidazoline receptors in the cardiovascular actions of moxonidine, rilmenidine and clonidine in conscious rabbits. Journal of Pharmacology and Experimental Therapeutics, 276: 411-420.

17. De Sarro GB, Ascioti C, Froio F, Libri V \& Nistico G (1987). Evidence that locus coeruleus is the site where clonidine and drugs acting at alpha1- and alpha2-adrenoceptors affect sleep and arousal mechanisms. British Journal of Pharmacology, 90: 675-685.

18. Reid JL (2001). Update on rilmenidine: clinical benefits. American Journal of Hypertension, 14 (Part 2): 322S-324S

19. Schann S, Bruban V, Pompermayer K, Feldman J, Pfeiffer B, Renard P, Scalbert E, Bousquet P \& Ehrhardt JD (2001). Synthesis and biological evaluation of pyrrolinic isosteres of rilmenidine: discovery of cis-/trans-dicyclopropylmethyl-(4,5-dimethyl-4,5-dihydro-3 Hpyrrol-2-yl)-amine (LNP 509), an $I_{1}$ imidazoline receptor selective ligand with hypotensive activity. Journal of Medical Chemistry, 44 1588-1593.

20. Bruban V, Estato V, Schann S, Ehrhardt JD, Monassier L, Renard P, Scalbert E, Feldman J \& Bousquet P (2002). Evidence for synergy between $\alpha_{2}$-adrenergic and nonadrenergic mechanisms in central blood pressure regulation. Circulation, 105: 1116-1121.

21. Kobinger W (1978). Central alpha-adrenergic systems as targets for hypotensive drugs. Reviews of Physiology, Biochemistry and Pharmacology, 81: 39-100

22. Dollery CT \& Reid JR (1973). Central noradrenergic neurones and 
the cardiovascular actions of clonidine in the rabbit. British Journal of Pharmacology, 47: 206-216.

23. Struijker-Boudier HA, Messing MW \& van Essen H (1996). Alphaadrenergic reactivity of the microcirculation in conscious spontaneously hypertensive rats. Molecular and Cellular Biochemistry, 157: 239-244.

24. Evenwel RT, Kasbergen CM \& Struyker-Boudier HAJ (1983). Central and regional hemodynamics and plasma-volume distribution during the development of spontaneous hypertension in rats. Clinical and Experimental Hypertension. Part A, Theory and Practice, 5: 15111536.

25. Suzuki H, Zweifach BW \& Schimid-Schönbein GW (1996). Glucocorticoid modulates vasodilator response of mesenteric arterioles in spontaneously hypertensive rats. Hypertension, 27: 114-118.

26. Schimid-Schönbein GW, Zweifach BW, DeLano FA \& Chen P (1987). Microvascular tone in a skeletal muscle of spontaneously hypertensive rats. Hypertension, 9: 164-171.

27. Suzuki H, Zweifach BW \& Schimid-Schönbein GW (1995). Vasodilator response of mesenteric arterioles to histamine in spontaneously hypertensive rats. Hypertension, 26: 397-400.

28. Brook RD \& Julius S (2000). Autonomic imbalance, hypertension, and cardiovascular risk. American Journal of Hypertension, 13 (Part 2): 112S-122S

29. Gootman MP, Gootman N \& Buckley BJ (1983). Maturation of central autonomic control of the circulation. Federation Proceedings, 42: 1648-1655.

30. Nyhof RA, Laine GA, Meiniger GA \& Granger HJ (1983). Splanchnic circulation in hypertension. Federation Proceedings, 42: 1690-1993.

31. Le Noble LML, Tangelder GJ, Slaaf DW, Smits JFM \& StruykerBoudier HAJ (1987). Adrenergic stimulation of the rat mesenteric vascular bed: a combined micro- and macrocirculatory study. Pflügers Archiv, 410: 250-256.

32. Lee RM, Forrest JB, Garfield RE \& Daniel EE (1983). Ultrastructural changes in mesenteric arteries from spontaneously hypertensive rats. A morphometric study. Blood Vessels, 20: 72-91.

33. Le Noble LML, Smits JFM, Slaaf DW, Tangelder GJ \& StruykerBoudier HAJ (1984). Effects of anesthesia on regional and microcirculatory hemodynamic effects of vasopressor substances in the rat. International Journal of Microcirculation, Clinical and Experimental, 3: 314-316.

34. Azevedo ER, Newton GE \& Parker JD (1999). Cardiac and systemic sympathetic activity in response to clonidine in human heart failure. Journal of the American College of Cardiology, 33: 186-191.

35. Dabire H \& Richer C (1991). Implication of the central nervous system in the systemic and regional hemodynamics of two centrally acting hypotensive drugs, flesinoxan and clonidine, in the rat. Journal of Cardiovascular Pharmacology, 18: 605-613.

36. El-Mas MM \& Abdel-Rahman AA (1999). Role of the sympathetic control of vascular resistance in ethanol-clonidine hemodynamic interaction in SHRs. Journal of Cardiovascular Pharmacology, 34: 589-596.

37. Bowery NG, Bettler B, Froestl W, Gallagher JP, Marshall F, Raiteri M, Bonner TI \& Enna SJ (2002). International Union of Pharmacology. XXXIII. Mammalian gamma-aminobutyric acid (B) receptors: structure and function. Pharmacological Reviews, 54: 247-264.

38. Williford DJ, DiMicco JA \& Gillis RA (1980). Evidence for the presence of a tonically active forebrain GABA system influencing central sympathetic outflow in the cat. Neuropharmacology, 19: 245-250.

39. Paes-da-Silva F, Gonzalez AP \& Tibiriçá E (2003). Effects of fluid resuscitation on mesenteric microvascular blood flow and lymphatic activity after severe hemorrhagic shock in rats. Shock, 19: 55-60.

40. Torres Filho IP, Contaifer Junior D, Garcia S \& Neves L da S (2001). Vasomotion in rat mesentery during hemorrhagic hypotension. Life Sciences, 68: 1057-1065. 